\title{
ESTIMATION OF QUASI-STATIC $J$-R CURVES FROM CHARPY ENERGY AND ADAPTATION TO ASTM E 1921 REFERENCE TEMPERATURE ESTIMATION OF FERRITIC STEELS
}

\author{
P.R. Sreenivasan ${ }^{1}$ \\ ${ }^{1}$ Metallurgy and Materials Group, Indira Gandhi Centre for Atomic Research, Kalpakkam, Tamilnadu, INDIA- \\ 603102 \\ E-mail of corresponding author: sreeprs@yahoo.co.in
}

\begin{abstract}
Many researchers had suggested a sort of scaling procedure for predicting the quasi-static $J$ - $R$ curves from dynamic $J-R$ curves obtained from instrumented Charpy V-notch (CVN) impact tests using key-curve, compliance or other procedures. Chaouadi, based on extensive tests and literature data, had quantitatively formalized the method and suggested general applicability of his method for a class of steels. In this paper, first, Chauoadi-procedure is tried on some selected data from the literature (including the data used by Chaouadi and other workers) and an adaptation of the method is suggested using Wallin's as well as Landes's lower bound methods for upper-shelf $J$ - $R$ curve estimation from CVN energy. Using Chaouadi and other data as the benchmark, suitable scaling factors have been determined that enable estimation of quasi-static $J-R$ curves from $C V N$ energy alone, without the need for dynamic CVN $J-R$ curves. The final formulae are given. This new method can be called modified Wallin-Landes procedure. Then this method is applied to fracture toughness and reference temperature $\left(T_{0}-\mathrm{ASTM}\right.$ E-1921) estimation from the full Charpy-transition data. The results are compared with those from the author's IGC-procedure, and modifications, if any, are suggested. Based on the new results, it is suggested that the IGC-procedure may be modified as: final $T_{\mathrm{Q} \text {-est }}=T_{\mathrm{Q}-\mathrm{IGC}}$ for $T_{\mathrm{Q} \text {-Sch }}{ }^{\mathrm{dy}} \leq 20{ }^{\circ} \mathrm{C}$ (in the IGC-procedure the dividing temperature was $60{ }^{\circ} \mathrm{C}$ ); and for $T_{\mathrm{Q}-\mathrm{Sch}}{ }^{\text {dy }}>20^{\circ} \mathrm{C}, T_{\mathrm{Q}-\mathrm{IGC}}=T_{\mathrm{Q}-\mathrm{WLm}}$ (different from the IGC-procedre and subscript WLm indicating modified Wallin-Landes procedure). For the 59 or more steels examined (including highly irradiated steels), the $T_{\mathrm{Q}-\mathrm{WL}}$ estimates at higher temperatures are consistent and conservative; a few non-conservative values are acceptably less than $20^{\circ} \mathrm{C}$, where as other predictions show non-conservatism of up to $40-50{ }^{\circ} \mathrm{C}$. At lower temperatures, $T_{\mathrm{Q}-\mathrm{IGC}}$ is consistently conservative and not over-conservative as the other estimates. The limitations suggested by Chaouadi for his method, namely, dependence on work-hardening, strain rate, yield stress, etc., hold good for the present method also and require further quantification based on finite element analysis, if necessary; however, these are not likely to affect the $T_{\mathrm{Q}}$ estimation significantly. $K_{\mathrm{J}-\mathrm{WLm}}$ is better than RNB correlation in making a conservative or closer estimate of fracture toughness at the upper shelf.
\end{abstract}

\section{INTRODUCTION}

Charpy V-notch impact (CVN) test is very attractive because of its low-cost, simplicity and wide familiarity and availability compared to the more sophisticated and costly fracture mechanics test which requires very skilled manpower and special instumentation [1,2]. For quantitative design involving assurance of structural integrity, fracture toughness data in terms of $K_{\mathrm{IC}}, J_{\mathrm{IC}}$ or, its engineering equivalent, $J_{0.2}$, and fracture resistance $J-R$ curves are required. To achieve this, many Charpy-fracture toughness correlations have been proposed; because of differences in loading rate, notch acuity, constraint etc. between the Charpy and fracture toughness tests, these lack universal applicability and are restricted to the specific material and test conditions for which they were derived [19]. However, some of the recent correlations are more promising from the point of view of producing design relevant fracture toughness properties that are consistently, and, often, assuredly, conservative [1,9]. This paper is an attempt to further extend these efforts. Aurich et al. [4] and Tronskar et al. [5] had suggested a sort of scaling procedure for predicting the quasi-static $J-R$ curves from dynamic $J-R$ curves obtained from instrumented CVN impact tests using key-curve, compliance or other procedures. They had given approximate scaling factors. Chaouadi $[1,6]$, based on extensive tests and literature data, had quantitatively formalized the method and suggested general applicability of his method for a class of steels. Chaouadi [1] had suggested the need for quantifying the variation of the scaling factors depending on work-hardening index, yield stress, strain rate etc., based on finite element analysis also. In this paper, using Chaouadi and other data as the benchmark, an adaptation of the method is suggested using Wallin's [7] as well as Landes' [8] methods for upper-shelf $J-R$ curve estimation from CVN energy. Methodolgy for obtaining the suitable scaling factors has been oulined that will enable estimation of quasi-static $J-R$ curves from CVN energy alone, without the need for dynamic CVN $J-R$ curves. The final formulae are given and the 
results discussed. This new method can be called modified Wallin-Landes procedure. Then this method is applied to fracture toughness and reference temperature ( $T_{0}-$ ASTM E-1921 [10]) estimation from the full Charpy-transition data. The results are compared with those from Sreenivasan's [9] IGC-procedure and modifications, if any, are suggested. Also, the effectiveness of the new formulae in predicting the upper-shelf fracture toughness is examined and compared with the results from the well known Rolfe-Novak-Barsom (RNB) equation [3].

\section{BASIC METHODOLOGY AND MATERIALS}

\section{Basic Methodology}

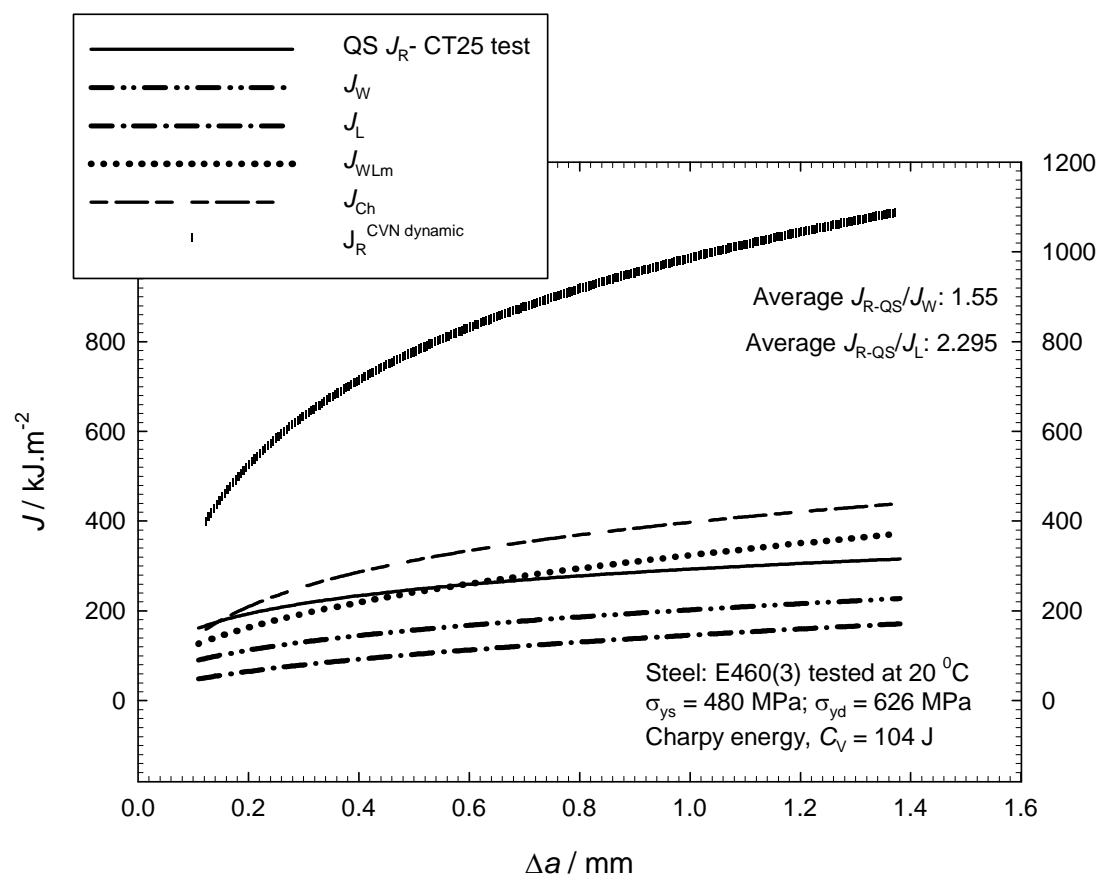

Fig. 1. Illustration of the Wallin and Landes procedure predictions and derivation of scaling factors

Aurich et al. [4] and Tronskar et al. [5] had suggested the possibility of obtaining quasi-static $J-R$ curves from dynamic $J-R$ curves obtained from instrumented impact tests of blunt-notched or precracked CVN specimens using appropriate scaling. The scaling factor was determined empirically, often with an additional factor involving the ratio of dynamic to static yield stress. Chaouadi and Puzzolante [1,6] had formalised these efforts in the following equations:

$$
J_{R}^{\text {static }}=\alpha_{\mathrm{LR}} \cdot \beta_{\text {config }} \cdot\left(\frac{\sigma_{\mathrm{yd}}}{\sigma_{\mathrm{ys}}}\right)^{2} . J_{R}{ }^{\mathrm{CVN} \text { impact }}
$$

which for dynamic $J_{R}$ reduces to:

$$
J_{R}{ }^{\text {dynamic }}=\beta_{\text {config }} . J_{R}{ }^{\mathrm{CVN} \text { impact }}
$$

where, $J_{\mathrm{R}}{ }^{\mathrm{CVN} \text { impact }}$, represents the dynamic $J_{\mathrm{R}}$-curve obtained from CVN impact test using key-curve, compliance or other procedures $[1,6,11]$ and $J_{\mathrm{R}}^{\text {dynamic }}$ and $J_{\mathrm{R}}^{\text {static }}$ are the dynamic and quasi-static $J_{\mathrm{R}}$-curves, respectively, obtained from deeply precracked specimens using standard fracture toughness tests; $\alpha_{\mathrm{LR}}$ is a loading rate factor, $\beta_{\text {conf }}$ is a factor accounting for notch acuity and configuration effects (V-notch vs. fatigue precrack), $\sigma_{\mathrm{yd}}$ and $\sigma_{\mathrm{ys}}$ are dynamic and static yield stress, respectively, at the test temperature. The square term arises from the consideration that $J_{\mathrm{R}}(J-$ resistance or crack resistance) is proportional to plastic zone size which is inversely proportional to the yield stress. 
Chauoadi [1] has empirically determined $\alpha_{\mathrm{LR}}=0.46 ; \beta_{\mathrm{conf}}$ is given to be 0.52 at quasi-static loading rate and 0.84 at impact loading rate. $J_{\mathrm{R}}^{\text {static }}$ obtained from Eq. (1) using Chaouadi's factors $\left(\alpha_{\mathrm{LR}}=0.46\right.$ and $\left.\beta_{\text {conf }}=0.52\right)$ may be termed $J_{\mathrm{Ch}}$. Figure 1 illustrates the application of Eq. (1) to the results for a C-Mn steel - E 460(3) - given in Aurich et al. [4].

Now, one disadvantage of the above procedure is that it requires instrumented impact test facility and sophisticated and careful data processing to obtain $J_{\mathrm{R}}{ }^{\mathrm{CVN} \text { impact }}$, that is, the dynamic $J_{\mathrm{R}}$-curve from CVN impact test. Recently, Wallin [7] as well as Gioielli, Landes et al. [8] have derived semi-empirical equations for estimating the static $J_{\mathrm{R}}$-curve from the CVN energy, $C_{\mathrm{V}}$ (because of the unfamiliarity and difficulty of the name Gioielli, for convenience, the procedure or equation due to the latter is referred as Landes' equation in this paper; Prof. Landes is well known in the elastic-plastic fracture field). Wallin's [7] near-lower-bound correlation for predominantly ductile fracture (especially applicable to Charpy upper-shelf - US - region) is applicable in the temeperature region -100 to $300{ }^{\circ} \mathrm{C}$. In fact, this new correlation gives not only the initiation $J$-value, but also the $J$ - $\Delta a$ tearing resistance curve $\left(J-R\right.$ curve) as a function of $C_{\mathrm{V}}$ values in the US. The correlations are as given below:

$$
J_{\mathrm{W}}=J_{1 \mathrm{~mm}} \Delta a^{\mathrm{m}}\left[\mathrm{kJ} \cdot \mathrm{m}^{-2}, \mathrm{~mm}\right]
$$

where

$$
J_{1 \mathrm{~mm}}=0.53 C_{\mathrm{V}-\mathrm{US}}^{1.28} \exp \left(-\frac{T-20}{400}\right)\left[\mathrm{kJ} . \mathrm{m}^{-2}, \mathrm{~J},{ }^{\circ} \mathrm{C}\right]
$$

and

$$
m=0.133 C_{\mathrm{V}-\mathrm{US}}^{0.256} \exp \left(-\frac{T-20}{2000}\right)-\frac{\sigma_{\mathrm{ys}-\mathrm{RT}}}{4664}+0.03\left[\mathrm{~J},{ }^{\circ} \mathrm{C}, \mathrm{MPa}\right]
$$

where $\sigma_{\mathrm{ys}-\mathrm{RT}}$ is the yield stress at room temperature, $C_{\mathrm{V} \text {-US }}$ is the upper-shelf $C_{\mathrm{V}}$ value and $T$ is the test temperature. The equation due to Landes [8] is as given below:

$$
J_{\mathrm{L}}=139.75\left(\frac{C_{\mathrm{V}-\mathrm{US}}}{3.15}\right)(\Delta a)^{0.5}\left[\mathrm{~kJ} \cdot \mathrm{m}^{-2}, \mathrm{~J}, \mathrm{~m}\right]
$$

The $J$ value from Eq. (3), that is due to Wallin, will be referred as $J_{\mathrm{W}}$, and that from Eq. (4), that is due to Landes, will be referred as $J_{\mathrm{L}}$. The $J_{\mathrm{W}}$ and $J_{\mathrm{L}}$ obtained for the steel in Fig. 1 are shown along with the quasi-static $J_{\mathrm{R}}$-curve $\left(\mathrm{QS}-J_{\mathrm{R}}\right.$ or $\left.J_{\mathrm{R}-\mathrm{QS}}\right)$.

As Eqs. (3) and (4) already incorporate a sort of notch effect and strain rate factors, only a simple multiplicative scaling is considered sufficient (unlike in the case of Eqs. (1) and (2)). The scaling factors are obtained by taking the ratios of $J_{\mathrm{R}-\mathrm{QS}} / J_{\mathrm{W}}$ and $J_{\mathrm{R}-\mathrm{QS}} / J_{\mathrm{L}}$; the average ratios obtained for the results in Fig. 1 are 1.55 and 2.295, respectively (i.e., over the whole range of $\Delta a=1.4-1.5 \mathrm{~mm}$ shown in Fig. 1). Similarly, ratios are found for various other steels. Other results and comparisons are given in detail later.

\section{Materials}

For calibration of the procedure, that is for determining the scaling factors as discussed in the previous paragraph, the data for the steels tested mainly at $20-25{ }^{\circ} \mathrm{C}$ or $280-300{ }^{\circ} \mathrm{C}$ and described in Aurich [4], Blauel [12], Eberle [13], Yoon [14] and El-Fadaly [15] have been used. For later comparison of the reference temperature estimates, apart from the above steels (only those for which full transition range Charpy data are available), all the steels described in Sreenivasan [9] have been used along with a few other steel data culled from recent literature, which are not listed here to restrict the bulk of the paper.

\section{RESULTS AND DISCUSSION}

\section{Modified Wallin-Landes Procedure for $\boldsymbol{J}_{\mathrm{R}}$ curve estimation}

For calibration, the scaling factors, $J_{\mathrm{R}-\mathrm{QS}} / J_{\mathrm{W}}$ and $J_{\mathrm{R}-\mathrm{QS}} / J_{\mathrm{L}}$, have been determined for the steels listed in Table 1. The average scaling factors are 1.656 and 2.146 for $J_{\mathrm{R}-\mathrm{Q} S} / J_{\mathrm{W}}$ and $J_{\mathrm{R}-\mathrm{QS}} / J_{\mathrm{L}}$, respectively, though for the particular steel shown in Fig. 1, they were 1.55 and 2.295, respectively. For the present purpose, for representing the material $J_{\mathrm{R}}$-curve, a mean value of $\left(1.656 J_{\mathrm{W}}+2.146 J_{\mathrm{L}}\right) / 2$ is proposed to be taken, where $J_{\mathrm{W}}$ and $J_{\mathrm{L}}$ are obtained from Eqs. (3) 
and (4) respectively. The $J_{\mathrm{R}}$-curve based on the mean value is called the $J$ based on modified Wallin-Landes procedure, represented by $J_{\mathrm{WLm}}$ (subscript indicating Wallin-Landes-modified). This is given as Eq. (5).

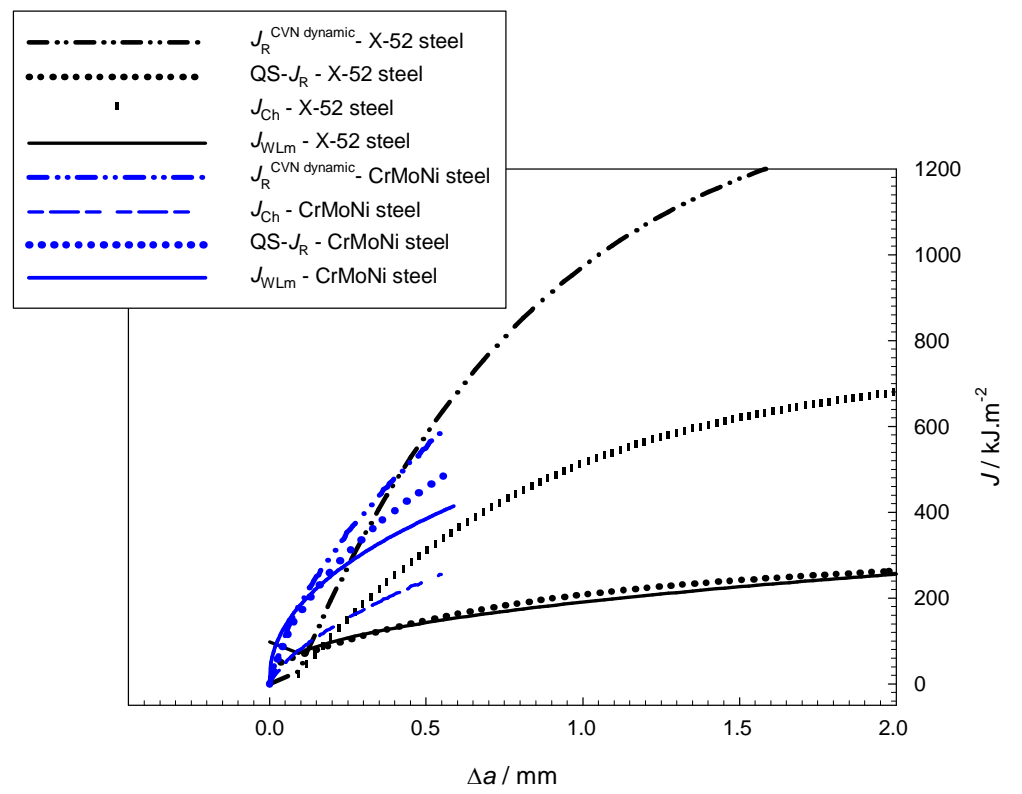

Fig. 2. Application of the modified Wallin-Landes procedure to an X-52 grade pipeline steel (Tyson et al. [16]) and a CrMoNi steel (Blumenauer et al. [17])

Table 1. Scaling factors determined for various steels (source references listed in square brackets)

\begin{tabular}{|c|c|c|c|c|c|}
\hline Steel & $J_{\mathrm{R}-\mathrm{Q} S} / J_{\mathrm{R}-\mathrm{W}}$ & $J_{\mathrm{R}-\mathrm{Q} S} / J_{\mathrm{R}-\mathrm{L}}$ & $\begin{array}{c}\text { Test } \\
\text { Temp } /{ }^{\circ} \mathrm{C}\end{array}$ & $C_{\mathrm{V}} / \mathrm{J}$ & $\mathrm{YS} / \mathrm{MPa}$ \\
\hline Eberle:St460 [13] & 1.8420 & 2.5130 & 25 & 78 & 470 \\
\hline Aurich:E460(3) [4] & 1.5500 & 2.2950 & 20 & 104 & 480 \\
\hline Blauel :20MnMoNi55[12] & 1.3880 & 1.8790 & 80 & 161 & 464 \\
\hline Blauel:20MnMoNi55 [12] & 1.3947 & 1.5992 & 150 & 155 & 441 \\
\hline Blauel:20MnMoNi55 [12] & 2.1073 & 1.6550 & 300 & 145 & 433 \\
\hline 20MnMoNi55:BM [15] & 1.6460 & 2.8230 & 25 & 194 & 454 \\
\hline 20MnMoNi55: -10\%PD [15] & 1.1390 & 1.9360 & 25 & 201 & 509 \\
\hline Yoon:Mod9Cr1Mo [14] & 1.7640 & 2.8340 & 25 & 187 & 520 \\
\hline Yoon:Mod9Cr1Mo [14] & 2.0732 & 1.7750 & 288 & 260 & 476 \\
\hline \multicolumn{7}{|c|}{ Computed values } & & \\
\hline Mean & 1.656 & 2.146 & & & \\
\hline SD & 0.325 & 0.485 & & & \\
\hline Std. Error & 0.108 & 0.162 & & & \\
\hline 95\% Confidence Level & 0.250 & 0.373 & & & \\
\hline 99\% Confidence Level & 0.363 & 0.543 & & \\
\hline
\end{tabular}

$$
J_{\mathrm{wLm}}=\frac{1.656 J_{\mathrm{W}}+2.146 J_{\mathrm{L}}}{2}
$$

In Fig. 1, the $J_{\mathrm{WLm}}$ curve shows fair agreement with the $J_{\mathrm{R}-\mathrm{QS}}$ curve; in fact, it shows much better agreement with the $J_{\mathrm{R} \text {-QS }}$ curve than the curve obtained by the Chaouadi procedure, $J_{\mathrm{Ch}}(\mathrm{Eq}$. (1)). For all the steels for which Chaouadi $[1,6]$ has demonstrated his method (i.e., Eq. (1)), the predictions from Eq. (5) are excellent when 
compared with the respective quasi-static $J_{\mathrm{R}}$ curves (all the data used in the present calibration are different from those used by Chaouadi). Hence, this agreement is very satisfactory.

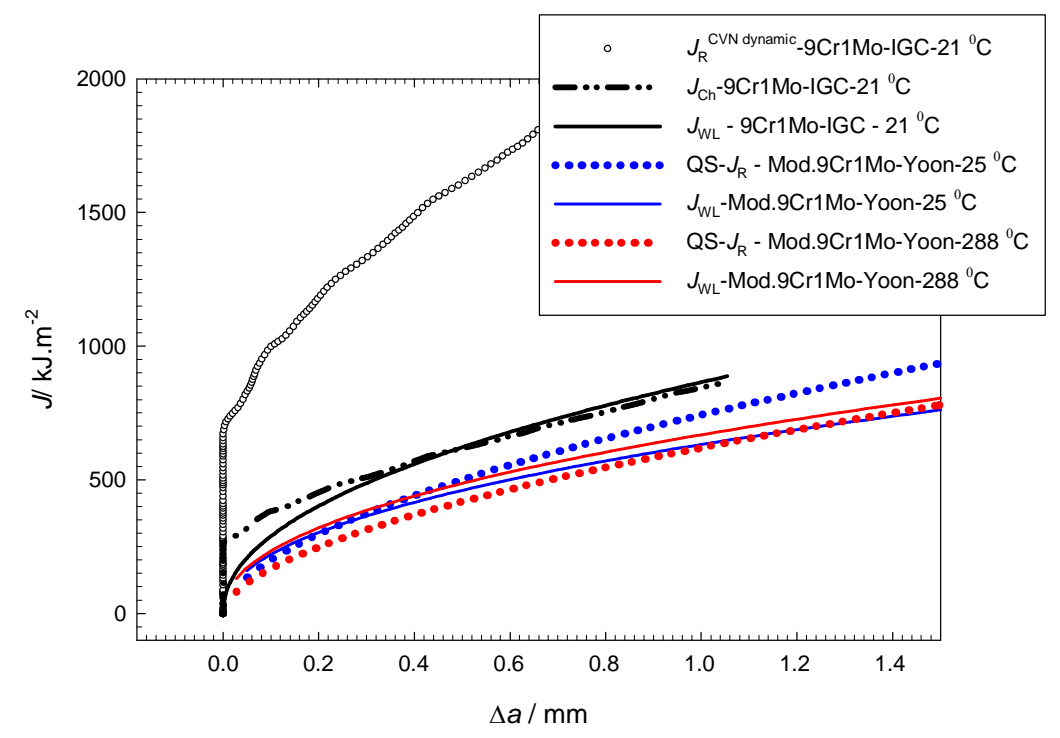

Fig. 3. Comparison of the $J_{\text {WLm }}$ with $J_{C h}$ or $J_{Q S}\left(Q S-J_{R}\right.$ ) for a 9Cr1Mo steel [18] and a modified 9 Cr1Mo steel [14]

In fact, for some different steels, for which the Chaouadi method doesn't work, use of Eq. (5) results in excellent agreement with the QS data. Two such cases are shown in Fig. 2. For the X-52 steel the agreement extends to very large crack extension upto 6-7 $\mathrm{mm}$ while for the CrMoNi steel, the the $J_{\mathrm{WLm}}$ curve is acceptably conservative at large crack extensions. The results for a $9 \mathrm{Cr} 1 \mathrm{Mo}$ steel [18] and a modified 9Cr1Mo steel [14] are presented in Fig. 3. The dynamic $J_{\mathrm{R}}$ curve for the $9 \mathrm{Cr} 1 \mathrm{Mo}$ steel shown in Fig. 3 was determined by Sreenivasan [18] from the instrumented impact test results of CVN (non-precracked) specimens by applying the key-curve procedure described in Sreenivasan et al. [11]; the agreement between the $J_{\mathrm{Ch}}$ and $J_{\mathrm{WLm}}$ curves is quite good. For the modified 9Cr1Mo steel (Yoon et al. [14]) shown in Fig. 3, the $25{ }^{\circ} \mathrm{C}$ results are acceptably (but not excessively) conservative (i. e., $\left.J_{\mathrm{WLm}}<J_{\mathrm{QS}}\right)$ while the $288^{\circ} \mathrm{C}$ results are non-conservative, but within the scatter expected for $J$ values - Sreenivasan et al. [19]. The relevant mechanical data for the steels shown in Figs. 2 and 3 are given in Table 2.

Table. 2. Relevant mechanical data for steels shown in Figs. 2 and 3 (source references listed in square brackets)

\begin{tabular}{|l|c|c|c|c|c|c|}
\hline Steel & $\begin{array}{c}\text { Test Temp/ } \\
{ }^{\circ} \mathrm{C}\end{array}$ & $\begin{array}{c}\text { YS / } \\
\mathrm{MPa}\end{array}$ & $\begin{array}{c}\text { Dy. YS / } \\
\mathrm{MPa}\end{array}$ & $C_{\mathrm{V}} / \mathrm{J}$ & $\begin{array}{c}\text { RT-YS / } \\
\text { MPa }\end{array}$ & Remarks \\
\hline X-52 (Tyson et al. [16]) & 23 & 376 & 554 & 65.5 & 376 & IIT $^{*}+$ QS $^{\#}$ \\
\hline CrMoNi (Blumenauer et al. [17]) & 25 & 447 & 603 & 160 & 447 & IIT+ QS \\
\hline 9Cr1Mo (Sreenivasan [18] & 21 & 515 & 668 & 244 & 515 & Only IIT \\
\hline Mod. 9Cr1Mo (Yoon et al. [14]) & 25 & 525 & 670 & 187 & 525 & No IIT \\
\hline Mod. 9Cr1Mo (Yoon et al. [14]) & 288 & 476 & 473 & 260 & 525 & No IIT \\
\hline
\end{tabular}

*: IIT - Instrumented Impact Test; \#: QS - Quasi Static

\section{Application of $\boldsymbol{K}_{\mathrm{J}-\mathrm{WLm}}$ for Estimation of ASTM E 1921 Reference Temperature ( $\left.\boldsymbol{T}_{\mathbf{0}}\right)$}

Modified Wallin-Landes procedure for $J_{\mathrm{R}}$ curve estimation was described in the previous section. One thing that emerges from the previous section is that though $J_{\mathrm{R}}$ curve by the Wallin-Landes procedure may differ from the actual QS $-J_{\mathrm{R}}$ curve (conservatively, and, sometimes, non-conservatively), the commonly used engineering estimate of $J, J_{0.2}$, may be close to the actual values. This is obtained by taking $\Delta a=0.2 \mathrm{~mm}$ in Eqs. (3)-(5); the 


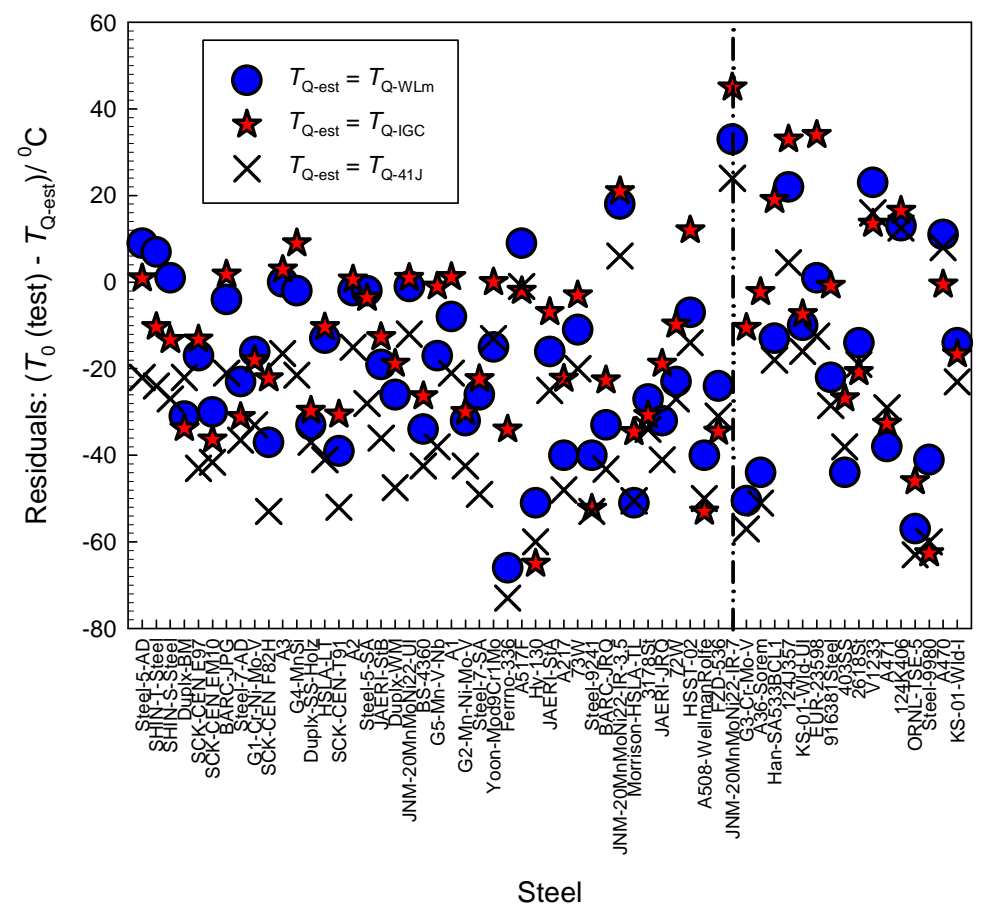

Fig. 4. Residuals various reference temperature estimates compared with that of $T_{\mathrm{Q}-\mathrm{WL}}$

corresponding $K_{\mathrm{J}-\mathrm{WLm}}$ can be estimated by the usual conversion formula $\left(K_{\mathrm{J}}=\sqrt{ } E J /\left(1-v^{2}\right)\right)$. Though Eqs. (3)-(5) have been resticted to be applicable to the fully ductile upper shelf, for our purpose we remove that restriction and apply the Eqs. (3)-(5) over the whole range of Charpy transition to obtain the corresponding $K_{\mathrm{J}}$, taking $\Delta \mathrm{a}=0.2 \mathrm{~mm}$. Then the $K_{\mathrm{J}-\mathrm{WLm}}$ values corresponding to the straight line portion of the CVN transition curve are taken to estimate an equivalent of $T_{0}$. This can be done by superimposing an eye-fit straight on the linear portion of the Charpy transition curve avoiding the lower shelf. Then starting from the lowest value on the straight line portion a range of values up to 50-70 $\mathrm{MPa} \sqrt{\mathrm{m}}$ above the lowest value are taken with the corresponding temperatures and these are applied to the multi-temperature Wallin formula(Eq. (6)) to yield an estimate of $T_{0}$, namely, $T_{\mathrm{Q}-\mathrm{wL}}$. Since all the calibrations given Table 1 pertain to $1 "$ thick quasi-static test, the $K_{\mathrm{J}-\mathrm{WLm}}$ values obtained from $J_{\mathrm{WL}}$ are considered as pertaining to $1 "$ specimen tests. Equation (6) is as given below [10,9]:

$$
0=\sum_{i=1}^{i=n} \frac{\delta_{i} \exp \left\{0.019\left(T_{i}-T_{0}\right)\right.}{\left[31-K_{\min }+77 \exp \left\{0.019\left(T_{i}-T_{0}\right)\right\}\right]}-\sum_{i=1}^{n} \frac{\left(K_{J-W L}-K_{\min }\right)^{4} \exp \left\{0.019\left(T_{i}-T_{0}\right)\right\}}{\left[31-K_{\min }+77 \exp \left\{0.019\left(T_{i}-T_{0}\right)\right\}\right]^{5}}
$$

where the Kronecker $\delta_{\mathrm{i}}=1, K_{\min }=20 \mathrm{MPa} \sqrt{\mathrm{m}}, T_{\mathrm{i}}$ is the test temperature and $T_{0}=T_{\mathrm{Q}-\mathrm{wL}}$. The validity conditions and other requirements as required by ASTM E 1921 [10] are not examined. The $K_{\mathrm{J}-\mathrm{wLm}}$ values for application in Eq. (6) range from 100-170 to 200-270 $\mathrm{MPa} \sqrt{\mathrm{m}}$, depending on the steel.

Figure 4 shows the residuals of the $T_{\mathrm{Q}-\mathrm{wL}}$ values (i. e., $T_{0}$ (test) $-T_{\mathrm{Q}-\mathrm{wL}}$ ) for about 59 steels (all steels mentioned in [9] plus some additional steels) in comparison with other estimates discussed in [9] ( $T_{\mathrm{Q}-\mathrm{IGC}}$ : $T_{\mathrm{Q} \text {-est }}$ based on the IGC procedure described by Sreenivasan [9] and $T_{\mathrm{Q}-41 \mathrm{~J}}$ : taking $T_{\mathrm{Q} \text {-est }}=T_{41 \mathrm{~J}}$, the $41 \mathrm{~J}$ Charpy transition temperature, a very conservative estimate). It can be seen that $T_{\mathrm{Q}-\mathrm{wL}}$ is either as much conservative or more over the whole range of $T_{0}$ values ranging from about -140 to $+140{ }^{\circ} \mathrm{C}$ examined in Fig. 4 . The steels in Fig. 4 are arranged with increasing $T_{\mathrm{Q}-\mathrm{Sch}}{ }^{\text {dy }}$ (a dynamic fracture toughness based reference temperature estimate as described in [9] which is necessary to estimate $\left.T_{\mathrm{Q}-\mathrm{IGC}}\right)$ from left to right ranging from -100 to $230{ }^{\circ} \mathrm{C}$. In fact, for the high temperature steels to the right of the vertical line shown in Fig. 4 (i. e., $T_{\mathrm{Q}-\mathrm{Sch}}{ }^{\mathrm{dy}}>\sim 20{ }^{\circ} \mathrm{C}$ ), $T_{\mathrm{Q}-\mathrm{wL}}$ shows more consistency in producing assuredly conservative values than $T_{\mathrm{Q}-\mathrm{IGC}}$. So the criterion given in [9] may be modified as: $T_{\mathrm{Q} \text {-est }}=T_{\mathrm{Q}-\mathrm{IGC}}$ for $T_{\mathrm{Q}-\mathrm{Sch}}^{\mathrm{dy}} \leq 20{ }^{\circ} \mathrm{C}$ and $T_{\mathrm{Q} \text {-est }}=T_{\mathrm{Q} \text {-wL }}$ for $T_{\mathrm{Q}-\mathrm{Sch}}{ }^{\mathrm{dy}}>20^{\circ} \mathrm{C}$. The limitations suggested by Chaouadi for 
his method, namely, dependence on work-hardening, strain rate, yield stress, etc., hold good for the present method also and require further quantification based on finite element analysis, if necessary; however, these are not likely to affect the $T_{\mathrm{Q}}$ estimation significantly.

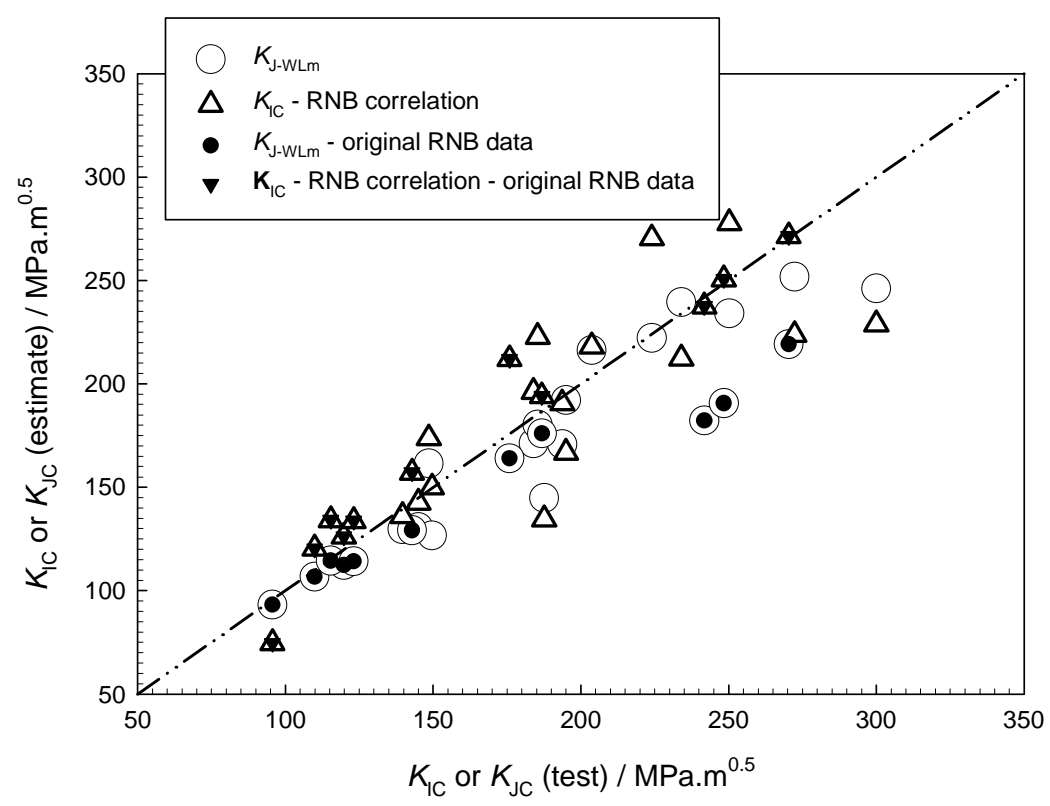

Fig. 5. Comparison of $K_{\mathrm{J}-\mathrm{WLm}}$ (for $\Delta a=0.2 \mathrm{~mm}$ ) at the upper shelf with the predictions from RNB correlation for 27 steels

\section{$K_{\mathrm{J}-W L m}$ as an Upper Shelf Fracture Toughness Estimator}

As described in the previous section, estimates of $J_{\mathrm{WLm}}$ values at the upper shelf corresponding to $\Delta a=0.2$ mm will give the upper shelf $K_{\mathrm{J}-\mathrm{WLm}}$ using the usual conversion formula. The results for 27 steels are shown in Fig. 5 in comparison with predictions from the RNB correlation [3]. The conservatism of the $K_{\mathrm{J}-\mathrm{wLm}}$ for all the steels is obvious - closer to or below the 1:1 line. In fact, the filled symbols shown in Fig. 5 pertain to the 11 steels that went into the original RNB correlation. $K_{\mathrm{J}-\mathrm{WLm}}$ is better than RNB correlation in making a conservative or closer estimate of fracture toughness at the upper shelf.

\section{CONCLUSION}

Chaouadi procedure predicts the quasi-static $J-R$ curves from dynamic $J-R$ curves obtained from instrumented Charpy V-notch (CVN) impact tests. Wallin and Landes formulae predict lower bound upper shelf fracture toughness and quasi-static $J$ - $R$ curves from CVN energy. Using Chaouadi and other data as the benchmark, suitable scaling factors have been determined that enable estimation of quasi-static $J-R$ curves from $C V N$ energy alone by application of the Wallin and Landes formulae, without the need for dynamic CVN $J$-R curves. The final formulae are given. This new method can be called modified Wallin-Landes procedure. Then this method is applied to fracture toughness and reference temperature ( $T_{0}$ - ASTM E-1921) estimation from the full Charpy-transition data. The results are compared with those from the author's IGC-procedure, and modifications, if any, are suggested. Based on the new results, it is suggested that the IGC-procedure may be modified as: final $T_{\mathrm{Q} \text {-est }}=T_{\mathrm{Q} \text {-IGC }}$ for $T_{\mathrm{Q}-\mathrm{Sch}}{ }^{\mathrm{dy}} \leq 20^{\circ} \mathrm{C}$ (in the IGC-procedure the dividing temperature was $60{ }^{\circ} \mathrm{C}$ ); and for $T_{\mathrm{Q}-\mathrm{Sch}}{ }^{\mathrm{dy}}>20^{\circ} \mathrm{C}, T_{\mathrm{Q}-\mathrm{IGC}}=$ $T_{\mathrm{Q}-\mathrm{WLm}}$ (different from the IGC-procedre and subscript WLm indicating modified Wallin-Landes procedure). For the 59 or more steels examined (including highly irradiated steels), the $T_{\mathrm{Q}-\mathrm{WL}}$ estimates at higher temperatures are consistent and conservative; a few non-conservative values are acceptably less than $20{ }^{\circ} \mathrm{C}$, where as other predictions show non-conservatism of up to $40-50{ }^{\circ} \mathrm{C}$. At lower temperatures, $T_{\mathrm{Q}-\mathrm{IGC}}$ is consistently conservative and not over-conservative as the other estimates. The limitations suggested by Chaouadi for his method, namely, dependence on work-hardening, strain rate, yield stress, etc., hold good for the present method also and require 
further quantification based on finite element analysis, if necessary; however, these are not likely to affect the $T_{\mathrm{Q}}$ estimation significantly. $K_{\mathrm{J}-\mathrm{WLm}}$ is better than RNB correlation in making a conservative or closer estimate of fracture toughness at the upper shelf.

\section{REFERENCES}

[1] R. Chaouadi and J.L Puzzolante. Procedure to Estimate the Crack Resistance Curve from the Instrumented Charpy V-Notched Impact Test. ICF-12, Toronto, Canada, 2009.

[2] Sreenivasan, P. R. Instrumented Impact Testing-Accuracy, Reliability, and Predictability of Data, Trans. Indian Inst. Met., Vol 49 (No. 5), Oct. 1996, pp. 677-696.

[3] Nevasmaa P and Wallin K. STRUCTURAL INTEGRITY ASSESSMENT PROCEDURES FOR EUROPEAN INDUSTRY SINTAP TASK 3 STATUS REVIEW REPORT: RELIABILITY BASED METHODS. REP. SINTAP VTT/4 (SINTAP-3-2-1997). VTT Manufacturing Technology, Espoo, Finland, March 1997.

[4] D. Aurich, R. Helms, H.-J. Kuhn, K. Wobst and J. Ziebs. Charpy upper shelf energy and crack resistance. Nuclear Engineering and Design, 87, 1985, pp.109-121.

[5] J.P. Tronskar, M.A. Mannan, M.O. Lai. Correlation between quasi-static and dynamic crack resistance curves. Engineering Fracture Mechanics, 70, 2003, pp.1527-1542.

[6] Chaouadi, J.L. Puzzolante . Loading rate effect on ductile crack resistance of steels using precrackedCharpy specimens, Int J Pres. Ves. Piping 85, 2008, pp.752-761.

[7] K. Wallin. Low cost J-R curve estimation based on CVN upper shelf energy, Fat Frac Eng Mat Struc., 24, 2001, pp.537-549.

[8] P.C. Gioielli, J.D. Landes, J.D. Paris, H. Tada, L. Loushin. Method for predicting J-R curves from Charpy impact energy, in: P.C. Paris, K.L. Jerina (Eds.) Fatigue and Fracture Mechanics: 30th Volume, ASTM STP 1360, 2000, pp. 61-68.

[9] Sreenivasan P R. Inverse of Wallin's relation for the effect of strain rate on the ASTM E-1921 reference temperature and its application to reference temperature estimation from Charpy tests. Nucl. Engng. and Design, 241, 2011, pp. 67-81.

[10] ASTM E1921-97. Standard test method for determination of reference temperature, $T_{0}$, for ferritic steels in the transition range. Annual Book of ASTM Standards, Vol. 03.01, 1998, pp.1060-1076. ASTM, Philadelphia, USA.

[11] P.R. Sreenivasan and S.L. Mannan. Dynamic $J-R$ curves and tension-impact properties of AISI 308 stainless steel weld. Int. J. Fracture, 101, 2000, pp. 229-249.

[12] J. G. Blauel, L. Hodulak, T. Hollstein \& B. Voss. Material Characterization by J-R Curves of a 20MnMoNi55 Forging. Int. J. Pres. Ves. \& Piping 17 (1984) 139-162.

[13] A. Eberle, D. Klingbeil, J. Schicker.The calculation of dynamic JR-curves from the finite element analysis of a Charpy test using a rate-dependent damage model. Nuclear Engineering and Design 198 (2000) 75-87.

[14] Ji-Hyun Yoon, and Eui-Pak Yoon.Fracture Toughness and the Master Curve for Modified 9Cr-1Mo Steel. METALS AND MATERIALS International, 12 (6), 2006, pp. 477-482.

[15] M.S. El-Fadaly, T.A. E1-Sarrage, A.M. Eleiche, W. Dahl. Fracture toughness of 20MnMoNi55 steel at different temperatures as affected by room-temperature pre-deformation.Journal of Materials Processing Technology, 54,1995, pp.159-165.

[16] W. R. Tyson, S. Xu and R. Bouchard. Correlation between J and CVN in upper shelf. In: From Charpy to Present Impact Testing (Charpy Centenary Conference, Poitiers, France, 2-5 Oct. 2001). D. Francois and A. Pineau (eds.). ESIS Publication 30, ESIS-Elsevier, Oxford OX5 IGB, UK, 2002, pp. 325-332.

[17] Horst Blumenauer, Elfrun Schick and Rainer Ortmann. Elastic-plastic fracture-mechanics assessment of a CrMoNi pressure vessel steel, Nuclear Engineering and Design, 130 (1991)pp.289-295.

[18] P. R. Sreenivasan. Unpublished results. MMG, IGCAR, Kalpakkam, India (2004).

[19] P. R. Sreenivasan, A. Moitra, S. K. Ray, S. L. Mannan. Dynamic Fracture Toughness Properties of a 9Cr-1Mo Weld from Instrumented Impact and Drop-weight Tests, International Journal of Pressure Vessels \& Piping, 69(1996) pp.149-159. 